\title{
DIALÉTICA DO ESCLARECIMENTO EM MINIATURA: A DOMINAÇÃO DA NATUREZA EM ALGUMAS IMAGENS DE PENSAMENTO DE WALTER BENJAMIN
}

Francisco de Ambrosis Pinheiro Machado

\begin{abstract}
RESUMO
Este artigo visa mostrar como certos aspectos da Dialética do esclarecimento (1944) de Adorno e Horkheimer, mais precisamente no que diz respeito ao conceito dominação da natureza, já aparecem elaborados, em miniatura e de forma germinal em algumas imagens de pensamento (Denkbild) do livro Rua de mão única (1928) de Walter Benjamin.

Palavras-chave: Benjamin. Adorno. Horkheimer. Imagem de Pensamento. Rua de mão Única. Dominação da Natureza. Dialética do Esclarecimento. Catástrofe. Crítica.
\end{abstract}

\section{DIALECTIC OF ENLIGHTENMENT IN MINIATURE: THE DOMINATION OF NATURE IN SOME IMAGES OF THOUGHT FROM WALTER BENJAMIN}

\begin{abstract}
This papper aims to show how some aspects of Adornos and Horkheimers Dialectic of Enlightment (1944), espcially concerning the notion of domination of nature, are still elaborated in a miniatural and seminal form in some thought-images (Denkbild) of Benjamins book One-way street (1928).
\end{abstract}

Keywords: Benjamin. Adorno. Horkheimer. Thought-image. One-way Street. Domination of Nature. Dialectic of Enlightment. Catastrophe. Critics. 


\section{Introdução}

Podendo ser considerado um experimento poético-político de inspiração surrealista, que se configura como uma resposta à crise cultural e política da República de Weimar, o livro "Rua de mão única"1 de Walter Benjamin, publicado em 1928, consiste em uma coleção de 60 fragmentos curtos, denominados de "imagens de pensamento" (Denkbilder). Por meio destas, Benjamin busca instaurar o que definiu, no ano seguinte, em seu ensaio sobre o surrealismo ${ }^{2}$, de "espaço de imagem" (Bildraum), no qual a realidade cotidiana, singular e concreta, apreendida normalmente de modo unilateral no contexto reificado da sociedade industrial moderna, é iluminada e percebida sob novas dimensões, abrindo-se como um local possível de crítica histórica e intervenção estético-política transformadora, justamente ali onde os modos tradicionais de crítica pareciam estar neutralizados.

Trata-se aqui, primeiramente, de explicitar as características da forma "imagem de pensamento", para então, num segundo momento, mostrar como esse modo figurativo de pensar o presente e a história permite a Benjamin diagnosticar e refletir criticamente sobre os impasses a que chegou a civilização ocidental esclarecida por conceber seu progresso, sob os auspícios da ciência e técnica modernas, como crescente dominação da natureza. Abordagem benjaminiana que antecipa, por assim dizer, a virada da teoria crítica realizada por Adorno e Horkheimer nos anos $1940^{3}$.

\section{Estrutura da imagem de pensamento e seu potencial crítico}

"PARA HOMENS

\author{
"FÜR MÄNNER
}

1 BENJAMIN. "Rua de mão única". In: Obras escolhidas II: Rua de mão única. (Tradução: Rubens Rodrigues Torres Filho). 4a. ed. São Paulo: Brasiliense, 1994, pp.9-70.

2 BENJAMIN. "O surrealismo: o último instantâneo da inteligência européia". In: Obras escolhidas I.: Magia e técnica, arte e política. (Tradução: Sérgio Paulo Rouanet).7a. ed. São Paulo: Brasiliense, 1994, pp. 21-35.

3 Cf. afirmação de Gérard Roulet: "A virada peculiar que Benjamin realizou na 'teoria crítica da sociedade', e que se tornará manifesta na Dialética do Esclarecimento (...), consiste em desmascarar as mais elevadas formas de socialização como recaída na violência da natureza. A completa dominação sobre a natureza aparece como o beco sem saída da dominação, como o fim de sua rua de mão única teleológica" (RAULET, Gérard. "Einbahnstrasse", p. 265.). Jeanne Marie Gagnebin também fala em uma "pequena Dialética do Esclarecimento e do sinistro", mas referindose especificamente à imagem de pensamento "Criança escondida" (GAGNEBIN, "Mímesis e crítica da representação em Walter Benjamin”, p.359).

Francisco de Ambrosis Pinheiro Machado - Doutor pela Universidade de Munique - Ludwig Maximilian, Professor da UNIFESP. Brasileiro, residente em São Paulo - SP, E-mail: francisco.pinheiro.machado@gmail.com 
A imagem de pensamento se caracteriza como uma forma breve, densa e assistemática de escrita literária e filosófica. Estrutura-se em duas partes: um título e um texto mais ou menos curto. O título é como uma imagem, um instantâneo ou fotografia de coisas concretas do mundo cotidiano. No caso de Rua de mão única: de palavras ou frases que encontramos em placas de trânsito, reclames, vitrines ou portas das casas quando andamos por uma rua de Berlim ou de outra cidade nos anos 1920. Por exemplo: "Posto de Gasolina", "Canteiro de obras", "Alemão bebe cerveja alemã", "Panorama imperial”, "No113", "Ao planetário". "Para homens", título da imagem de pensamento citada acima, poderia estar na porta de um cabeleireiro ou de uma loja de roupas masculinas. O texto, por sua vez, contém pensamentos e reflexões comprimidos em frases e metáforas intensas, que são uma espécie de comentário ao título. O texto da imagem de pensamento citada, o mais curto do livro, consiste em uma afirmação categórica da infertilidade da argumentação discursiva ou especulativa. Afirmação que se intensifica por jogar com um sentido que não aparece na tradução em português: "convencer" em alemão é "Überzeugen", termo composto por "über" (sobre, além, mais de) e "zeugen" (produzir, procriar; testemunhar, apresentar provas) podendo por isso ser lido não só como "comprovar argumentativamente ou por testemunhos que se colocam acima dos argumentos da outra parte, levando esta a mudar de conviçção", mas também, como "produzir ou procriar em excesso". Neste último sentido, que não é o usual, teríamos uma espécie de paradoxo: "produzir ou procriar em excesso é algo infrutífero ou estéril". Paradoxo que dá nova vida e amplitude à imagem de pensamento como um todo ao tencionar, num outro nível, o erótico, o texto-comentário com a referência do título ao sexo masculino. Note-se que por meio da crítica à produtividade excessiva e à argumentação especulativa esta imagem de pensamento justifica a si mesma enquanto forma breve e concisa ao mesmo tempo que remete para além de si, no caso: para a prolixidade da literatura da época, bem como para a produção e

\footnotetext{
4 BENJAMIN. "Rua de mão única". In: op. cit., p. 14.

5 BENJAMIN. "Einbahnstraße". In: agora como GS). . Gesammelte Schriften, Vol. IV., p.87. (Citado, a partir de
} 
consumo em massa na sociedade industrializada ${ }^{6}$. A riqueza semântica e potencial crítico desse modo figurativo de pensamento devem-se, entre outros, a esse seu caráter monadológico. É este que permite à imaginação e ao pensamento explorar as inúmeras interpolações e extrapolações possíveis contidas nos meandros de cada fragmento.

Convém, para compreender a peculiaridade da imagem de pensamento, apontar algumas semelhanças e diferenças com outras formas breves e/ou figurativas de escrita.

A imagem de pensamento é muito próxima do aforismo. Este, segundo Werner Helmich, "é uma forma literária de prosa, concisa, isolada de um contexto, destituída de ficção narrativa e provida de uma 'pointe', isto é, um efeito estilístico destinado a obter no leitor uma surpresa estética ou gnosiológica" ${ }^{7}$, efeito, vale notar, que pode "provocar seja uma revalorização mais ou menos profunda das próprias convicções, seja uma risada, ou ambas"8. Desta definição de aforismo, podemos dizer que a imagem de pensamento só não compartilha da ausência de narrativas, de exemplos, ou de qualquer coisa que não seja pura reflexão ${ }^{9}$. Em alguns fragmentos, por exemplo, Benjamin narra sonhos ou lembranças de sua infância. Essa diferença ganha importância quando considerada junto à dupla estrutura da imagem de pensamento (título e texto), onde ocorre um jogo entre textocomentário e título (como imagem, ou extrato do concreto) inexistente no aforismo.

Do ponto de vista da estrutura e deste jogo, a imagem de pensamento corresponde antes à alegoria ou ao emblema barroco que, além de breves e isoladas, também se dividem em duas partes, a saber: de um lado pictura (imagem),

${ }^{6}$ Interpretação que se torna mais palpável quando se tem em mente outras imagens de pensamento do livro que abordam de modo mais explícito esses conteúdos. O tema do papel da literatura e do crítico literário no contexto da sociedade industrial é talvez o principal do livro e recorrente em um grande número de imagens de pensamento. A título de exemplo: quanto à relação entre literatura, convicção e fertilidade, conferir já a primeira imagem de pensamento do livro "Posto de gasolina"; quanto à literatura e prolixidade, ver a irônica "Material escolar: princípios dos catataus ou arte de fazer livros grossos": BENJAMIN. "Rua de mão única". In: op. cit., respectivamente, p. 11 e p. 29. Quanto à referência sociedade industrial e de massas, será desenvolvida no decorrer deste trabalho.

7 HELMICH. "L'aforisma come genere letterario", p. 31.

8 HELMICH. op.cit., p.40.

9 HELMICH. op.cit., p. 39. Werner Helmich não trata aqui das imagens de pensamento de Walter Benjamin, mas cita, por exemplo, a forma das Minima Moralia de Adorno, como uma forma híbrida entre aforismo e ensaio brevíssimo.

Francisco de Ambrosis Pinheiro Machado - Doutor pela Universidade de Munique - Ludwig Maximilian, Professor da UNIFESP. Brasileiro, residente em São Paulo - SP, E-mail: francisco.pinheiro.machado@gmail.com 
de outro, a inscriptio (lema, moto, ou nome do conceito representado) contendo ainda, em alguns casos, a subscriptio (epigrama) - esta última conteria uma descrição e explicação do sentido que cada parte da imagem possui em relação ao conceito ou ideia moral que está sendo representado, reforçando a interpretação dada no lema ${ }^{10}$. Além disso, imagem de pensamento, alegoria e emblema são formas heterogêneas e fragmentadas, que se situam na ausência de unidade de sentido entre o mundo sensível e pensamento, ou seja, não se fundam numa totalidade harmônica como a suposta no símbolo ${ }^{11}$. Há, no entanto, duas diferenças fundamentais entre estas formas.

Em primeiro lugar, enquanto na alegoria e no emblema o concreto ou a imagem sensível deste aparece como natureza (por exemplo, uma árvore com frutos, para representar uma ação moral boa), na imagem de pensamento o que se manifesta é a sociedade, como segunda natureza reificada ${ }^{12}$. Nesse sentido, Heinz Schlaffer, em estudo onde aborda as características da imagem de pensamento enquanto condizente com a teoria crítica da sociedade, baseando-se não só em Benjamin, mas também identificando esta forma em textos de Kracauer (Die Angestellte), Bloch (Spuren), Brecht (Herr Keuner), Adorno (Minima moralia) e Horkheimer (Dämmerung), afirma que "na imagem de pensamento, o conhecimento da sociedade deve necessariamente se colocar. (...) Atrás da máscara de cada individualização estão agindo, na verdade, as leis gerais abstratas da sociedade"13. Basta verificarmos alguns títulos das imagens de pensamento benjaminiana para identificar de imediato como elas implicam em um conhecimento da sociedade e mais especificamente da sociedade moderna industrializada. Além dos títulos acima citados, vale lembrar outros como: "Relógio normal", "Material escolar", "Armas e

\footnotetext{
${ }^{10}$ Sobre estrutura da alegoria, emblema e divisa, forma anterior a esta, conferir: HANSEN, João Adolfo. Alegoria: construção e interpretação da metáfora. São Paulo: Hedra; Campinas: Editora Unicamp, 2006. Cf. também: BAFFETT. "Le teorie del motto nei trattati sugli emblemi e sulle emprese". In: RIGONI, Mario Andrea (Org.). La brevitá felice. Venezia: Marsilio Editori, 2006, pp. 149-150.

${ }^{11}$ Sobre a oposição entre alegoria e símbolo instituída pelo romantismo, ver: BENJAMIN, Walter. Origem do drama barroco alemão. São Paulo: Brasiliense, 1985.

12 "Les formes du XXe siècle, image de pensée et miniature, introduisent à l'opposé des formes barroques, des dissonances e des oppositions marquées entre la pensée et le fragment imagé de la réalité - qui, en outre, ne leur apparaît pás comme nature, mais comme société, come seconde nature réifiée" (FÜRNKÄS, Josef. "Image de pensée et miniature selon W. Benjamin", p. 289.).

${ }^{13}$ SCHLAFFER."Denkbilder: eine kleine Prosaform zwischen Dichtung und Gesellschaftstheorie", pp.143-144.
} 
munição", "Alarme de incêndio", "Policlínica", "Mendigos e ambulantes proibidos!", "Lâmpada de arco". Essas remissões à sociedade também aparecem, algumas vezes mais, outras menos explicitamente, nos textos-comentários, inclusive nos relatos de sonhos de Benjamin, nas lembranças de sua infância ou nas referências a suas relações amorosas. Como diz Adorno: na imagem de pensamento "justamente àquelas experiências, que para uma perspectiva trivial seriam meramente subjetivas, é atribuído objetividade, mais, que o subjetivo é apreendido em absoluto só como manifestação de algo objetivo" ${ }^{14}$. Por isso, independente de estarem explícitos nos títulos ou nos textos-comentários, aqueles conteúdos sociais concretos e objetivos são intrínsecos à estrutura da imagem de pensamento.

Em segundo lugar, na alegoria barroca, imagem e inscrição/epigrama buscam suprir mutuamente sua carência de unidade: a inscrição ou o epigrama explicitam o conceito que a imagem sensível apresenta suprimindo sua ambiguidade, e a imagem torna um conceito acessível concreta e imediatamente aos sentidos. A alegoria busca, desse modo, estabelecer uma correspondência harmônica entre imagem e inscrição/epigrama, tentando arbitrariamente restaurar aquela unidade teológica do símbolo que foi perdida e apreender o mundo em sua totalidade. A imagem de pensamento, ao contrário, funda-se na dissonância e oposição que há entre título e texto, buscando aumentar a tensão entre elas. Ela explora essa oposição e heterogeneidade com intenção crítica e aberta, recusando-se a apreender o mundo numa totalidade harmônica fechada e exigindo um esforço reflexivo do pensamento diante do caráter enigmático que essa oposição gera e mantém sem solução.

Por isso, segundo Adorno, imagem de pensamento benjaminiana não deve ser entendida como alegoria platônica, como evocações metafóricas de coisas indizíveis em palavras, mas como "imagens-enigmas" (Vexierbilder), que não devem interromper o pensamento conceitual, mas, muito pelo contrário:

Por meio de sua forma de enigma chocar e com isso colocar o pensamento em movimento, pois este em sua forma conceitual tradicional parece estarrecido, convencional e envelhecido. $\mathrm{O}$ que não se deixa demonstrar em estilo corrente e, no entanto, submete, deve incitar a espontaneidade e a energia do pensamento, bem como, sem ser tomado literalmente, deve por

${ }^{14}$ ADORNO. "Benjamins Einbahnstrasse", p. 27.

Francisco de Ambrosis Pinheiro Machado - Doutor pela Universidade de Munique - Ludwig Maximilian, Professor da UNIFESP. Brasileiro, residente em São Paulo - SP, E-mail: francisco.pinheiro.machado@gmail.com 
meio de um curto-circuito intelectual acender faíscas, que desde sempre iluminam sob um novo aspecto o familiar (das Vertraute umbeleuchten), quando não o colocam em chamas ${ }^{15}$.

É desse modo que a imagem de pensamento pode responder à exigência de um novo tipo de crítica, capaz de fazer frente ao poderio persuasivo do reclame e do olhar mercadológico, que predomina da Alemanha dos anos 1920, tal como Walter Benjamin diagnostica na imagem de pensamento "ESTAS ÁREAS SÃO PARA ALUGAR". O título aponta para espaços livres, mas que são destinados à propaganda e cuja ocupação tem um preço, remete, portanto, para uma liberdade bastante ambígua.

O texto-comentário, por sua vez, refletirá sobre a complexa posição do crítico diante desta ambiguidade:

\begin{abstract}
Insensatos os que lamentam o declínio da crítica. Pois sua hora há muito tempo já passou. Crítica é uma questão de correto distanciamento. Ela está em casa em um mundo em que perspectivas e prospectos vêm ao caso e ainda é possível adotar um ponto de vista. As coisas nesse meio tempo caíram de maneira demasiado abrasante sobre o corpo da sociedade humana. A 'imparcialidade', o 'olhar livre' são mentiras, quando não são a expressão totalmente ingênua de chã incompetência. $O$ olhar mais essencial hoje, o olhar mercantil que penetra no coração das coisas, chamase reclame. Ele desmantela o livre espaço de jogo da contemplação (...). O que, afinal, torna os reclames tão superiores à crítica? Não aquilo que diz a vermelha escrita cursiva elétrica - mas a poça de fogo que a espelha sobre 0 asfalto ${ }^{16}$.
\end{abstract}

Não podendo mais o crítico se colocar em posição distanciada de seu objeto, como exigiria a crítica nos moldes clássicos, ele deve então recriar ativamente essa distância, fazendo uso oportuno tanto dos espaços livres deixados pelo reclame, quanto da própria estrutura deste. Pois, em sua estrutura dupla, a imagem de pensamento imita e pode ao mesmo tempo distorcer criticamente o reclame para provocar a reflexão e se contrapor a ele, ou seja: o título da imagem de pensamento mimetizaria a escrita elétrica, vertical e ditatorial do reclame para penetrar nas condições sociais dadas e expô-las concretamente, enquanto que o textocomentário corresponde ao reflexo daquela escrita, agora horizontalizada e desfigurada sobre o asfalto, explorando criticamente e a contrapelo o potencial

\footnotetext{
${ }^{15}$ ADORNO. "Benjamins Einbahnstrasse", pp. 27-28.

${ }^{16}$ BENJAMIN. "Rua de mão única". In: op. cit., p. 54-55. Tradução com algumas modificações minhas. (Cf. GS IV, p. 131-132).
}

Francisco de Ambrosis Pinheiro Machado - Doutor pela Universidade de Munique - Ludwig Maximilian, Professor da UNIFESP. Brasileiro, residente em São Paulo - SP, E-mail: francisco.pinheiro.machado@gmail.com 
incendiário do reclame ${ }^{17}$. É esta crítica atuante ${ }^{18}$ que, a meu ver e divergindo em parte de Adorno, para quem Benjamin estaria negando a distância como um todo ${ }^{19}$, é possibilitada pela imagem de pensamento.

É assim que a imagem de pensamento remete à sociedade moderna industrial em sua concretude cotidiana, bem como tem um caráter disruptivo, semelhante à imagem surrealista ou à iluminação profana, gerado pela intensificação da oposição entre título e texto que instiga o pensamento a apreender como um enigma e sob novas dimensões aquela realidade concreta reificada e fechada. Em função dessas características, a imagem de pensamento possibilitaria instaurar uma espécie de "distanciamento na proximidade" ou uma "historização do sem-história ou do naturalizado" como base para uma crítica no interior mesmo deste contexto reificado em que se situa e contra o qual a crítica tradicional não tem como atuar.

\section{Dominação da natureza e catástrofe}

Podemos agora verificar a eficácia crítica deste gênero de escrita figurativa e disruptiva que Benjamin ajudou a fundar ${ }^{20}$. Para tal, gostaria de expor como a imagem de pensamento permitiu a Benjamin elaborar, de dentro mesmo de seu contexto social e com elementos concretos deste, um diagnóstico crítico da República de Weimar em particular e do capitalismo industrial avançado em geral,

\footnotetext{
${ }^{17}$ Cf. interessante leitura que Luciano Gatti faz desta imagem de pensamento, chegando a conclusões muito próximas das defendidas aqui: "A relação entre o título e o texto é equivalente àquela entre $o$ anúncio e seu reflexo no asfalto. $O$ anúncio mercantil passa a funcionar como o ensejo para a recolocação da atividade de crítica, e portanto, para uma intervenção na escrita urbana, reunindo o distanciamento da crítica do passado com a necessidade combativa, alheia à neutralidade, de uma crítica à altura do presente. A montagem de reclames e textos que caracteriza a Rua de mão única não os reconcilia, mas mantém a distância entre a linguagem publicitária e a do crítico. Essa distância permite perceber o quanto a crítica está sedimentada em tal situação histórica, mas busca reagir a ela. Nesse sentido, Rua de mão única é um livro voltado para a produção de uma nova perspectiva da cidade: ele utiliza os anúncios publicitários, mas contra a ordem social que os produz, buscando nessa oposição um novo espaço para o exercício da crítica" (GATTI, Luciano. "Walter Benjamin e o Surrealismo: escrita e iluminação profana", pp. 79-80.).

${ }^{18}$ Willi Bolle define-a como "crítica militante". Cf. BOLLE. Fisiognomia da metrópole moderna: Representação da história em Walter Benjamin, p. 162.

${ }^{19}$ Para Adorno, quer parecer que Benjamin cairia naquilo que Anna Freud denominou de "identificação com o agressor", quando nesta imagem de pensamento "nega o conceito de crítica e o contrasta, em nome de uma práxis coletiva, com o que ele mesmo tinha mais horror, conduzindo se em um passo por demais familiar com o espírito do tempo" (ADORNO W. "Benjamins Einbahnstrasse", p. 32.).

${ }^{20}$ Cf. RAULET. "Einbahnstrasse", p. 359.
}

Francisco de Ambrosis Pinheiro Machado - Doutor pela Universidade de Munique - Ludwig Maximilian, Professor da UNIFESP. Brasileiro, residente em São Paulo - SP, E-mail: francisco.pinheiro.machado@gmail.com 
que, entre outros, expõe como a crise e risco de aniquilamento desta sociedade está vinculada ao ímpeto mítico de domínio total da natureza. Esse diagnóstico, como veremos, exige uma revisão de certas posições do materialismo histórico sobretudo no que diz respeito ao risco da ideologia do progresso técnico-científico e apontaria, por isso, para a virada na teoria crítica da sociedade, que ocorreu 20 anos mais tarde a partir da Dialética do Esclarecimento de Adorno e Horkheimer. Duas imagens de pensamento serão diretamente analisadas aqui: "Panorama imperial" e "Ao planetário".

O título "PANORAMA IMPERIAL (KAISERPANORAMA)" nos coloca diante de um grande aparelho cilíndrico, difundido por Fuhlmann, em torno do qual o público de umas 20 pessoas podia se sentar e apreciar por um binóculo 50 imagens transparentes estereoscópicas (tridimensionais) iluminadas dentro do cilindro, que iam se alternando de uma para outra. Eram fotos de paisagens pitorescas, de monumentos arquitetônicos, de cidades distantes, de festas oficiais famosas, em geral inacessíveis à maioria das pessoas. Em função do grande número destes aparelhos que circulavam pela Alemanha e Europa na segunda metade do século XIX, pode-se imaginar o fascínio que exercia para um cidadão comum europeu da época. Benjamin descreve, em Infância em Berlim por volta de 1900, num fragmento com o mesmo título, seu encantamento quando criança com estes "aquários do distante e do passado", onde "crianças estreitavam amizade com o globo terrestre" 21 mesmo depois que estes aparelhos não estavam mais em seu auge e perdiam espaço para o cinema.

Cito, para caracterizar o que está em jogo no 'fragmento de realidade' implicado neste título, um pequeno trecho daquela descrição:

Certa vez [diz Benjamin], quis me persuadir, em frente de uma transparência da cidadezinha de Aix, que eu já teria brincado sob a luz cor de oliva, que se derramava através das folhas dos plátanos, na larga Avenida Mirabeau, numa época que, na verdade, nada compartilhara com outras fases de minha vida. Pois isso era singular naquelas viagens: seus mundos distantes nem sempre eram estranhos, e a saudade que despertavam em mim nem sempre era um chamariz ao desconhecido, mas antes, por vezes, aquele desejo mais suave de voltar a casa. Isso, porém,

${ }^{21}$ BENJAMIN. "Infância em Berlim por volta de 1900". In: Obras escolhidas II: Rua de mão única, p. 76. (GS IV, 240.) 
talvez fosse resultado da luz de gás, que caía tão suavemente sobre todas as coisas ${ }^{22}$.

O título "Panorama imperial", assim, evoca uma visão em perspectiva, com profundidade histórica e geográfica, convida a uma experiência da distância, do passado, de abertura para mundos estranhos, para o desconhecido, e também para o próximo, o familiar quando revitalizado pela distância - a vontade de voltar ao lar.

Exatamente o oposto de tudo isso é o que vamos encontrar no textocomentário desta imagem de pensamento. A começar pelo subtítulo: "viagem pela inflação alemã", que já indica se tratar de um diagnóstico da situação calamitosa da Alemanha após a I Guerra Mundial: abalada moralmente pela derrota, onerada pelo pagamento das dívidas de guerra, com inflação altíssima, desemprego, grande número de mendigos e soldados mutilados pelas ruas, com sistema político parlamentarista, mas bastante instável e isolada no que diz respeito à política externa.

Essa situação de isolamento político, bem como de depressão econômica e social da Alemanha, para Benjamin, era comparável a de uma cidade antiga quando cercada de inimigos, a espera do aniquilamento ou de um milagre. Para Benjamin, no entanto, o problema não está na crise e na situação de declínio em si do momento, mas em algo anterior: no apego obstinado à segurança e às posses, que tornaria a maioria dos burgueses alemães sem coragem e inteligência para ver na crise não uma catástrofe iminente, mas uma nova espécie de estabilidade, ou seja, uma chance de transformação das relações sociais anteriores, mesmo que isso estivesse aparentemente na esfera do extraordinário.

O caminho para o aniquilamento fica mais evidente, quando este apego filisteu, desesperado e mesquinho às próprias posses acaba por perverter até os instintos vitais humanos, tornando-os alheios à vida e sua conservação:

Onde o obscuro impulso do animal - como o narram inúmeras anedotas encontra saída do perigo que se aproxima e que ainda parece invisível, ali essa sociedade, da qual cada um tem em mira unicamente seu próprio e inferior bem-estar, sucumbe, como massa cega, com inconsciência animal, mas sem o inconsciente saber dos animais, a cada perigo, mesmo o mais próximo, e a diversidade dos alvos individuais se torna irrelevante perante a identidade das forças determinantes. Repetidamente se mostrou que seu

${ }^{22}$ BENJAMIN. "Infância em Berlim por volta de 1900". In: op.cit., p. 77. (GS IV, 240)

Francisco de Ambrosis Pinheiro Machado - Doutor pela Universidade de Munique - Ludwig Maximilian, Professor da UNIFESP. Brasileiro, residente em São Paulo - SP, E-mail: francisco.pinheiro.machado@gmail.com 
apego à vida habitual, agora já perdida há muito tempo, é tão rígido que frustra a aplicação propriamente humana do intelecto, a previdência, mesmo no perigo mais drástico. ${ }^{23}$

O mais assustador na crise do pós-guerra, portanto, é o embotamento do espírito, a falta de imaginação, de visão em perspectiva e discernimento históricos, gerados pelo medo de se desprender do habitual, do familiar, do confortável, mesmo quando este já não existe mais. Isso é que torna a massa mais cega e ignorante que os animais e por isso mais sujeita à barbárie e auto-aniquilamento. Em oposição à experiência aberta que a fantasia de uma criança permite ter com o outro, com os mundos desconhecidos apresentados pelos estereoscópicos do Panorama Imperial, Benjamin vai descrever o alemão do pós-I-Guerra, como um homem sem imaginação, sem capacidade de ironia, diálogo e sociabilidade, vivendo num fechamento e isolamento triplo: como indivíduo isolado dos outros, submetido heteronomamente à massa irracional; como sociedade e cultura fechada em si, incapaz de dialogar com outros países, culturas e épocas históricas; e, por fim, como ser humano hostilmente desvinculado da natureza (exterior e interior), na medida em que sua relação com esta seria de exploração ávida.

Quanto a este último tipo de isolamento, ele é exposto do seguinte modo nas linhas finais de "Panorama imperial":

\begin{abstract}
Dos mais antigos usos dos povos parece vir a nós como uma advertência: na aceitação daquilo que recebemos tão ricamente da natureza, guardarnos do gesto da avidez. Pois não somos capazes de presentear à mãe natureza nada que nos é próprio. Por isso convém mostrar reverência no tomar, restituindo, de tudo que desde sempre recebemos, uma parte a ela, antes ainda de nos apoderar do nosso. Essa reverência se manifesta no antigo uso da libatio. Aliás, é talvez essa mesma antiqüíssima experiência ética que se conserva, transformada, na proibição de juntar as espigas esquecidas e de recolher cachos de uvas caídos, uma vez que estes fazem proveito à terra ou aos antepassados, dispensadores de bênçãos. (...) Uma vez degenerada a sociedade, sob desgraça e avidez, a tal ponto que ela só pode ainda receber os dons da natureza pela rapina, que ela arranca os frutos imaturos para poder trazê-los vantajosamente ao mercado e que ela tem que esvaziar toda a bandeja somente para ficar saciada, sua terra empobrecerá e o campo trará más colheitas. ${ }^{24}$
\end{abstract}

Com este último passo, o diagnóstico crítico de Benjamin ganha uma dimensão que vai além do contexto específico da República de Weimar e se

\footnotetext{
${ }^{23}$ BENJAMIN. "Rua de mão única". In: op. cit., p. 21.

${ }^{24}$ BENJAMIN. "Rua de mão única". In: op. cit., p. 21. (GS IV, 101)
}

Francisco de Ambrosis Pinheiro Machado - Doutor pela Universidade de Munique - Ludwig Maximilian, Professor da UNIFESP. Brasileiro, residente em São Paulo - SP, E-mail: francisco.pinheiro.machado@gmail.com 
desenvolve numa crítica mais ampla de um progresso civilizatório fundado na dominação e exploração exaustiva da natureza e na ameaça de revolta desta, ameaça de aniquilamento não só dos alemães, mas da própria humanidade. Essa crítica à relação do homem com a natureza e essa advertência, que Benjamin em "Panorama imperial" faz ressoar pelo contraste entre sociedades antigas e modernas, são retomadas, não por acaso, na última imagem de pensamento do livro, intitulada "Ao planetário", onde aparece também uma tomada de posição mais nítida de Benjamin.

O título "AO PLANETÁRIO (ZUM PLANETARIUM)" remete a uma placa indicando a direção ou o caminho que leva a um local fechado, com uma cúpula em meia esfera onde são projetadas as constelações, movimentos dos planetas e outros fenômenos celestes e do espaço sideral. Trata-se de um equipamento bastante avançado, que expõe aos espectadores os conhecimentos adquiridos pela astronomia. Esse título soa, por isso, como um convite atraente para apreciarmos o espetáculo destes fenômenos celestes não mais observando diretamente 0 firmamento, mas por meio de uma simulação visual e didática, que também permite nos apropriar dos últimos conhecimentos astronômicos.

O texto-comentário irá apresentar, por sua vez, o oposto à indicação de um caminho para algo edificante e aparentemente inofensivo, problematizando o modo peculiar de como o homem urbano de uma sociedade moderna se relaciona com os astros e com a natureza em geral. Essa tensão entre o título, ou seja, entre um fragmento concreto do cotidiano social na República de Weimar, com o textocomentário será instaurada e explorada, como em "Panorama imperial", por meio de um contraste entre mundo antigo e moderno. Segundo Benjamin, a experiência do homem antigo com o cosmos se dava em comunidade e por meio da embriaguez, "na qual nos asseguramos unicamente do mais próximo e do mais distante, e nunca de um sem o outro". Com a astronomia moderna (Kepler, Copérnico, Tycho Brahe) o vínculo do homem com o universo passa a ser ótico, ao mesmo tempo que aquela experiência de embriaguez coletiva é descartada como algo irrelevante, sendo relegada ao indivíduo isolado no seu "devaneio místico em belas noites estreladas". Para Benjamin, essa negligência gera um abismo entre homem e natureza que, numa espécie de revolta, sempre de novo ameaça e assola povos e gerações, como 
foi o caso, no mundo moderno, da I Guerra Mundial. Esse "descaminho dos modernos" (Verirrung der Neueren) se explica, mais concretamente, pelo modo como a técnica passa a ser utilizada e concebida na modernidade.

Nesta, a técnica chegou a um estágio de desenvolvimento que permitiria uma nova relação de união (núpcias) da humanidade em escala planetária com as potências da natureza, mas justamente porque submetida à "avidez de lucro da classe dominante" e, para cumprir essa função, porque concebida de modo imperialista como "dominação da natureza", traiu a humanidade e resultou em uma catástrofe como a da guerra ${ }^{25}$. Avidez de lucro, exploração e dominação da natureza, como fundamento de um modo econômico e intensificadas numa situação de catástrofe causada por eles mesmos, são aqui, como em "Panorama imperial", o núcleo da crise da República de Weimar e da humanidade em geral.

Nesta última imagem, no entanto, Benjamin assume uma posição nova diante deste diagnóstico, posição que também torna mais claro o modo como compreende a recorrência ao mundo antigo e ao passado nestas imagens. A alternativa para Benjamin, não seria negar totalmente as conquistas da ciência e da técnica modernas num retorno romântico ao modo de vida dos antigos e em uma recaída no mito. Ao contrário, Benjamin defende que um novo tipo de experiência cósmica, um tipo moderno de embriaguez poderia ocorrer pela própria técnica, caso esta for compreendida não como dominação sobre a natureza, mas como ordenação das relações entre natureza e humanidade ${ }^{26}$. Por um lado, a embriaguez moderna retomaria a amplitude do conceito de natureza dos antigos, muito diferente da dos modernos: "o calafrio da genuína experiência cósmica não está ligado àquele minúsculo fragmento de natureza que estamos habituados a denominar 'natureza'”27. Por outro, não se trata mais da relação de povos e famílias com a natureza, mas da humanidade como um todo. Isso significa que essa nova

\footnotetext{
${ }^{25}$ Cf. BENJAMIN. "Rua de mão única". In: op. cit., p. 69. (GS IV, 147)

${ }^{26}$ Cf.: "Dominação da natureza, assim ensinam os imperialistas, é o sentido de toda a técnica. Quem, porém, confiaria em um mestre escola que declarasse a dominação das crianças pelos adultos como o sentido da educação? Não é a educação, antes de tudo, a indispensável ordenação da relação entre gerações e, portanto, se se quer falar de dominação, a dominação das relações entre gerações, e não das crianças? E assim, também a técnica não é dominação da natureza: é dominação da relação entre natureza e humanidade" (BENJAMIN. "Rua de mão única". In: op. cit., p. 69. (GS IV, 147.)).

${ }^{27}$ BENJAMIN. "Rua de mão única". In: op. cit., p. 69. (GS IV, 147.)
} 
ordenação das relações entre humanidade e natureza implicaria também em uma reordenação ou revolução das relações dos homens entre si, das relações sociais, o que para Benjamin estaria nas mãos do proletariado e de sua disciplina. A este caberia a tarefa de impedir a destruição do homem causada pela esterilidade de uma produção e exploração em excesso regida pela avareza ao reconduzir a humanidade e o trabalho humano para uma relação fecunda e criativa com a natureza. Este vínculo entre revolução proletária e embriaguez, Benjamin reafirma na máxima que encerra esta imagem e o livro: "o vivente só sobrepuja a vertigem do aniquilamento na embriaguez da procriação (Zeugung)"28. Postura que reverberará nas teses "Sobre o conceito de história", onde, remetendo a Fourier, defende "um tipo de trabalho que, longe de explorar a natureza, libera as criações (Schöpfungen) que dormem, como virtualidades, em seu ventre" 29 .

Vemos assim, que a crítica materialista propiciada por meio das imagens de pensamento em Rua de mão única, revela o modo já peculiar com o qual Benjamin nessa época começava a se vincular e se apropriar das posições do materialismo histórico e que marcará sua recepção deste em toda a sua obra. Ou seja, apontando tanto para o elemento de embriaguez (paixão) e de recorrência ao passado inspirada na teologia (rememoração) que o ato revolucionário envolve, e revendo de antemão a noção de que a revolução seria um momento culminante do progresso técnico e científico da humanidade, isso porque sobretudo a partir da modernidade estes foram concebidos como dominação da natureza. Ao que Benjamin opõe a noção de revolução como interrupção deste processo que estaria levando a humanidade ao aniquilamento em escala planetária. É nesse sentido que Benjamin, na imagem de pensamento "Alarme de incêndio" (Feuermelder) afirma: "Antes que a centelha chegue à dinamite, é preciso que o pavio que queima seja cortado" ${ }^{30}$.

Sob este ponto de vista, Benjamin chega a um diagnóstico crítico da sociedade, que aponta para um momento central no conceito de dialética do esclarecimento, por meio do qual Adorno e Horkheimer nos anos 40 realizaram uma

\footnotetext{
${ }^{28}$ BENJAMIN. "Rua de mão única". In: op. cit., p. 69. (GS IV, 147.)

${ }^{29}$ BENJAMIN. "Sobre o conceito de história". In: Obras escolhidas I.: Magia e técnica, arte e política, p. 228. (GS I, 699.)

30 BENJAMIN, "Rua de mão única". In: op. cit., p. 46. (GS IV, 122.) É nesse sentido que Michel Löwy retira desta imagem de pensamento o título para seu precioso comentário das teses "Sobre o conceito de história". Cf. particularmente: LÖWY, Walter Benjamin: aviso de incêndio, p. 23.
} 
virada na teoria crítica da sociedade. Ali, os autores expõem, em um movimento argumentativo semelhante, como o Esclarecimento, cuja meta era, por meio da sua concepção de progresso da ciência e da técnica, abolir toda forma de superstição, ilusão ou fantasia irracional, destruindo o mito e tirando o medo do homem para fazê-lo senhor da natureza, conduziu a terra a um estado catastrófico. Esse fenômeno, definido como um momento intrínseco à dialética do esclarecimento e à própria razão, não se limitando por isso ao período histórico da llustração, teria seu fundamento na imbricação entre esclarecimento e mito. Isso porque ambos, numa busca obsessiva de superar o medo do desconhecido, das potências obscuras da natureza, se fundam no impulso de dominação desta e na tentativa de apreensão do mundo como algo estabelecido e imutável, bem como controlável. Ao eterno retorno e à ordem estabelecida dos deuses no mito corresponderiam as leis universais da natureza e a fixação nos fatos da ciência de cunho positivista, cuja tarefa se limitaria a somente observar, classificar e calcular 0 imediatamente dado com fins pragmáticos de controle. Por isso:

na pregnância da imagem mítica como na clareza da fórmula científica a eternidade do factual é confirmada e a existência nua declarada como o sentido que ele bloqueia. O mundo como um juízo analítico gigantesco, o único dentre todos os sonhos da ciência que resta é da mesma têmpera que o mito cósmico, que vincula a mudança da primavera e outono com o rapto de Perséfone. ${ }^{31}$

O esclarecimento mais que oposição seria, assim, a "radicalização da angústia mítica" ${ }^{32}$. A consequência desse medo seria de que ao homem esclarecido, como ao homem mítico, restaria somente garantir sua auto-conservação por meio da adaptação cega àquele mundo eterno e imutável. O que corresponde, na dimensão política e social, à manutenção das relações de dominação e coerção social, características da sociedade reificada e de massas. Ou seja, a continuação do descaminho histórico que estaria levando a humanidade ao aniquilamento, agora de forma mais ampla e terrível como foi a II Guerra Mundial. É nesse sentido que Adorno e Horkheimer afirmam que "a maldição do progresso ininterrupto é a

\footnotetext{
${ }^{31}$ ADORNO, HORKHEIMER, Dialektik der Aufklärung, p. 33.

${ }^{32}$ ADORNO, HORKHEIMER, Dialektik der Aufklärung, p. 29.
}

Francisco de Ambrosis Pinheiro Machado - Doutor pela Universidade de Munique - Ludwig Maximilian, Professor da UNIFESP. Brasileiro, residente em São Paulo - SP, E-mail: francisco.pinheiro.machado@gmail.com 
regressão ininterrupta" ${ }^{33}$ e que por isso a tarefa histórica seria a interrupção deste processo histórico.

Não estamos distantes, portanto, daquele homem regredido, descrito por Benjamin já nos anos 1920, que se apega medrosa e mesquinhamente às suas posses e a seus interesses privados, visando somente sua auto-conservação, sem coragem e inteligência para perceber que a catástrofe está justamente em reiterar o medo obsessivo do desconhecido, medo sobre o qual seu mundo habitual foi construído. Seu apego à segurança embota-lhe o espírito e o impede de vislumbrar na própria crise a chance para uma revolução na trajetória histórica da humanidade. Desse modo é que podemos dizer que Benjamin, no esforço de formular uma experiência estética da história como alternativa à coisificação ${ }^{34}$, elabora imagens de pensamento que anteveem em miniatura a crítica histórica que torna manifesta a dialética do esclarecimento.

Certamente, Adorno e Horkheimer, nos anos 40, não compartilham mais da crença na revolução. Defendem, antes, que a interrupção histórica deve ocorrer enquanto autorreflexão da razão, cabendo garantir o resto de liberdade e autonomia ainda possível. Não obstante, seja na estrutura, seja no diagnóstico crítico e em sua busca de alternativa, a imagem de pensamento também já elabora a seu modo e em seu contexto específico aquela autorreflexão da razão. Nela vai se delineando, nas palavras de Olgária Matos:

\begin{abstract}
uma nova figura de racionalidade que dê conta, a um só tempo, da evidência e do desejo de controle cartesiano, como também do enigma, uma racionalidade que concilie Eros, Logos e Cronos, os desejos, a razão abstrata e o tempo, tornados antagônicos pela hipertrofia da racionalidade controladora. (...) Só assim o mito recalcado no interior da razão abstrata pode ser dissipado. É ele que retorna e se realiza como razão instrumental, lógica do lucro e logocentrismo. O domínio da natureza e da história que se desenvolve a um grau traumático aparece como a quintessência de uma mutilação vingativa da natureza exterior e interior. Uma razão reconciliada com a natureza pacificadora da destrutividade e da violência e redentora de suas potencialidades emancipadoras, associa e emancipa a sensibilidade, imaginação e razão. E assim, ela se traduz numa razão histórica que não é nem linha reta nem descaminho, mas enfrenta a encruzilhada entre a evidência (cartesiana) e o enigma da história ${ }^{35}$.
\end{abstract}

\footnotetext{
${ }^{33}$ ADORNO, HORKHEIMER, Dialektik der Aufklärung, p. 42.

${ }^{34}$ Cf. FÜRNKÄS, "Image de pensée et miniature selon W. Benjamin", p. 298.

${ }^{35}$ MATOS, Olgária C. F.. "Desejo de evidência, desejo de vidência", p. 126.
}

Francisco de Ambrosis Pinheiro Machado - Doutor pela Universidade de Munique - Ludwig Maximilian, Professor da UNIFESP. Brasileiro, residente em São Paulo - SP, E-mail: 
A meu ver, a brevidade feliz que caracteriza a imagem de pensamento consiste em apontar em cada ocasião decisiva, em cada encruzilhada histórica, de modo oportuno e fecundo, mesmo que negativamente, para a utopia desta razão reconciliada. Daí também a sua atualidade.

Francisco de Ambrosis Pinheiro Machado - Doutor pela Universidade de Munique - Ludwig Maximilian, Professor da UNIFESP. Brasileiro, residente em São Paulo - SP, E-mail: francisco.pinheiro.machado@gmail.com 


\section{REFERÊNCIAS}

ADORNO, Theodor W. "Benjamins Einbahnstrasse". In: Über Walter

Benjamin. Frankfurt a.M.: Suhrkamp, 1990, p. 27-33.

ADORNO, Theodor; HORKHEIMER, Max. Dialektik der Aufklärung. Frankfurt a.M.: Fischer, 1998.

BAFFETTI, Giovanni. "Le teorie del motto nei trattati sugli emblemi e sulle emprese". In: RIGONI, Mario Andrea (Org.). La brevitá felice. Venezia: Marsilio Editori, 2006, pp. 149-150.

BENJAMIN, Walter. Gesammelte Schriften, Vol. I e IV. Frankfurt a.M.: Suhrkamp, 1991.

BENJAMIN, Walter. Obras escolhidas II: Rua de mão única. (Tradução: Rubens Rodrigues Torres Filho). 4a. ed. São Paulo: Brasiliense, 1994.

BENJAMIN, Walter. Obras escolhidas I.: Magia e técnica, arte e política. (Tradução: Sérgio Paulo Rouanet).7a. ed. São Paulo: Brasiliense, 1994.

BENJAMIN, Walter. Origem do drama barroco alemão. São Paulo: Brasiliense, 1985.

BOLLE, Willi. Fisiognomia da metrópole moderna: Representação da história em Walter Benjamin. São Paulo: Edusp, 1994.

FÜRNKÄS, Josef. "Image de pensée et miniature selon W. Bejamin". In: RAULET, Gérard; FÜRNKÄS, Josef. Weimar: le tournant esthétique. Paris: Antrophos, 1988, pp. 288-299.

GAGNEBIN, Jeanne-Marie. "Mímesis e crítica da representação em Walter Benjamin”. In: DUARTE, Rodrigo e FIGUEIREDO, Virgínia (Orgs.) Mímesis e expressão. Belo Horizonte: Ed. UFMG, 2001, pp. 353-363.

GATTI, Luciano. "Walter Benjamin e o Surrealismo: escrita e iluminação profana". In: ARTEFILOSOFIA, Ouro Preto, vol. 6, pp. 74-94, 2009.

HANSEN, João Adolfo. Alegoria: construção e interpretação da metáfora. São Paulo: Hedra; Campinas: Editora Unicamp, 2006.

HELMICH, Werner. "L'aforisma come genere letterario". In: RIGONI, Mario Andrea (Org.). La brevitá felice. Venezia: Marsilio Editori, 2006, pp. 29-49.

LÖWY, Michel. Walter Benjamin: aviso de incêndio. Uma leitura das teses "Sobre o conceito de história". São Paulo: Boitempo, 2005.

MATOS, Olgária C. F.. "Desejo de evidência, desejo de vidência". In: Discretas esperanças: Reflexões filosóficas sobre o mundo contemporâneo. São Paulo: Nova Alexandria, 2006, pp. 101-127. 
RAULET, Gérard. "Einbahnstrasse". In: LINDNER, Burkhardt (Org.). BenjaminHandbuch: Leben-Werk-Wirkung. Stuttgart/Weimar: Metzler, 2006, p. 359-373.

SCHLAFFER, Heinz."Denkbilder: eine kleine Prosaform zwischen Dichtung und Gesellschaftstheorie". In: KUTTENKEULER, Wolfgang (Org.). Poesie und Politik: zur Situation der Literatur in Deutschland. Stuttgart/Berlin/Köln/Mainz: Kohlhammer, 1973, pp.137-154. 